\title{
Editor's note 18(4)
}

\author{
Amy G. Mazur ${ }^{1}$
}

Accepted: 1 October 2020 / Published online: 15 October 2020 (c) Springer Nature Limited 2020

With this issue, we are closing out a banner year for the journal in the midst of one of the most tumultuous years in living memory. It is a testimony to the vibrant health of our French Politics community that scholars continue to collaborate on such intellectually stimulating and important projects during such challenging times, important for the study of French Politics and the wider discipline of Political Science. And this issue is no exception. If anything, this is the most impactful special issue on which I have worked since I took up the helm of the journal in summer 2019, following Robert Elgie's untimely passing.

First, thanks to the leadership of midcareer women political scientists who have taken a conscientious decision to mentor emerging scholars, ALL of the contributions to this issue come from newly minted $\mathrm{PhDs}$ or $\mathrm{PhD}$ candidates. Thus, this issue represents the unquestionable vitality of our field. So, many thanks to both Jennifer Fredette, the guest editor of the special issue, and Isabelle Guinaudeau for taking on this all important mentoring role.

Second, this issue dialogs directly with the methodological project of the multimethods movement in political science more broadly speaking. As the issue's title indicates, the special issue has brought the case study approach back-in in the same way that Theda Skocpol and her contemporaries brought the focus on the state "back-in" to the subfield of Comparative Politics. That is, using rich, in-depth, interdisciplinary case study analysis not to prop up outmoded notions of French exceptionalism with pure description, but to strengthen ongoing concept and theory development outside of the study of French Politics and in doing so advance simultaneously an international and global Political Science and French Politics. Thus, the very scientific agenda that Emiliano Grossman, Robert Elgie and I identified as the goal of French Politics research in the OUP Handbook Project on the Study of French Politics published in 2016, which is just now appearing in paperback and so more accessible for teaching and scholarship.

The introductory article to the four articles in the special issue adeptly crafted by Jennifer Fredette places the four articles within the convergence between the rise of a multi-methods movement in US Political Science that has shown the promise of

Amy G. Mazur

mazur@wsu.edu

1 Logan, UT, USA 
the case study approach for rigorous theory-building; a new generation of French politics scholars who are dedicated to combining deep expertise with a broad understanding of core concepts and theories; and a field that has at its core pushing the envelope on what some have called the "French touch" contribution to theory-building and knowledge cumulation in political science. Fredette also draws attention to the concepts with which each author engages and advances through their fascinating articles. Each article in of itself presents an empirically rich theoretical puzzle.

It is important to point out that this has been a highly collaborative project from the start that took advantage of the infrastructure built in conjunction with the journal as a result in large part of Robert Elgie's legacy and vision. The four papers came out of an American Political Science Association-French Politics Group preconference workshop held at the 2019 meetings. These four scholars were invited to present their dissertation research and were given feedback by senior scholars at the workshop about how to turn their work into article worthy work. Indeed, the senior-junior collaboration is one of the things that caught my eye and allowed me to extend an invitation to Jennifer and her colleagues to submit a special proposal. And after that, senior and mid-level scholars as reviewers have made additional rigorous recommendations for significant revisions and came out more than satisfied with the final products. The high quality of each article individually and the special issue together speaks volumes to the integrity of the process and the dedication of all who participated in it since Jennifer Fredette first put the idea into action nearly two years ago.

The review article on internal political party processes by Florence EccormierNocca, a PhD candidate at Sciences Po Paris, resonates with the goals of special issue as well. Isabelle Guinaudeau, our review editor, recruited an emerging scholar and worked with her to produce an important review of recent research that opens up "the secret garden" of political parties and their crucial roles as linchpins in the democratic process through the lens of work on French political parties in a comparative perspective.

I invite you to read-on and to share with me how impressed and proud I am of this new generation of scholars who are carrying forward the core research agenda of an impactful and meaningful study of French Politics.

Amy G. Mazur, Lead Editor

Logan, Utah

September 30th, 2020 